\title{
CROP TYPE CLASSIFICATION USING VEGETATION INDICES OF RAPIDEYE IMAGERY
}

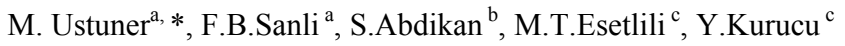 \\ ${ }^{a}$ Yildiz Technical University, Faculty of Civil Engineering, Department of Geomatic Engineering, 34220 Istanbul, Turkey - \\ (mustuner,fbalik)@yildiz.edu.tr \\ ${ }^{\mathrm{b}}$ Department of Geomatics Engineering, Bulent Ecevit University, 67100 Zonguldak, Turkey- sabdikan@beun.edu.tr \\ ${ }^{c}$ Ege University, Faculty of Agriculture, Department of Soil Science and Plant Nutrition, 35100 Bornova-İzmir/ Turkey- \\ (tolga.esetlili, yusuf.kurucu)@ ege.edu.tr
}

Commission VII, WG VII/4

KEY WORDS: Vegetation indices, RapidEye, NDVI, NDRE, GNDVI, SVM

\begin{abstract}
:
Cutting-edge remote sensing technology has a significant role for managing the natural resources as well as the any other applications about the earth observation. Crop monitoring is the one of these applications since remote sensing provides us accurate, up-to-date and cost-effective information about the crop types at the different temporal and spatial resolution. In this study, the potential use of three different vegetation indices of RapidEye imagery on crop type classification as well as the effect of each indices on classification accuracy were investigated. The Normalized Difference Vegetation Index (NDVI), the Green Normalized Difference Vegetation Index (GNDVI), and the Normalized Difference Red Edge Index (NDRE) are the three vegetation indices used in this study since all of these incorporated the near-infrared (NIR) band. RapidEye imagery is highly demanded and preferred for agricultural and forestry applications since it has red-edge and NIR bands. The study area is located in Aegean region of Turkey. Radial Basis Function (RBF) kernel was used here for the Support Vector Machines (SVMs) classification. Original bands of RapidEye imagery were excluded and classification was performed with only three vegetation indices. The contribution of each indices on image classification accuracy was also tested with single band classification. Highest classification accuracy of $87,46 \%$ was obtained using three vegetation indices. This obtained classification accuracy is higher than the classification accuracy of any dual-combination of these vegetation indices. Results demonstrate that NDRE has the highest contribution on classification accuracy compared to the other vegetation indices and the RapidEye imagery can get satisfactory results of classification accuracy without original bands.
\end{abstract}

\section{INTRODUCTION}

Sustainable management of the agricultural areas is crucial for local authorities and agricultural agencies since agriculture plays an important role at the economy of many developing countries (Branca, 2011).

Crop mapping and identification provide an important basis for many agricultural applications with various purposes such as yield estimation, crop rotation records and soil productivity (Löw et al. 2013, Fundamental of Remote Sensing). At this point, remote sensing technology helps us to derive accurate and reliable information about the crop types at the different spatial and temporal domain. Remotely sensed images at the different level of resolution from different types of sensors have been extensively and successfully used for crop mapping and identification since the first earth observation satellite Landsat1 was launched in 1972 (Bauer and Cipra 1973, Jewell 1989, Mulla 2013). Increasing demand of deriving quick, accurate, up-to-date and cost-effective information about the land cover has pushed the countries to launch new earth observation satellites such as RapidEye (2008), GeoEye-1 (2008), WorldView-2 (2009), Landsat8 (2013), SPOT-7 (2014) as optical imaging and, TerraSAR-X (2007), Sentinel-1A (2014) and ALOS-2 (2014) as radar imaging.
The common point of the optical sensors launched for environmental monitoring and assessment such as agriculture and forestry is to incorporate the near-infrared (NIR) band.

RapidEye, has been used here for crop type classification, is the first high-resolution multispectral satellite system incorporating the red-edge band which is sensitive to vegetation chlorophyll content (Schuster et al. 2012). This satellite imagery has been successfully used for classification of vegetation, forestry and agricultural areas recently (Eitel et al. 2011, Schuster et al. 2012, Tigges 2013, Löw et al. 2013).

Eitel et al. (2011) examined the broadband, red-edge information from RapidEye satellite for early stress detection. Schuster et al. (2012) tested the potential of the RapidEye red edge channel for improving the land use classification of the study site west of Berlin. Tigges et al. (2013) investigated the different spectral and temporal band combinations of RapidEye images for urban vegetation classification. Löw et al. (2013) implemented the SVM classification of RapidEye time series to impact the feature selection on the accuracy of crop classification.

Spectral vegetation indices in remote sensing have been widely used for the evaluation of biomass, water, plant and crops (Jackson and Huete, 1991). Vegetation indices of RapidEye imagery such as normalized difference vegetation index 
(NDVI) and the Normalized Difference Red Edge Index (NDRE) has been investigated in a few study (Eitel et al. 2011; Marx 2013). Therefore it is necessary to explore the potential use of vegetation indices of RapidEye imagery for crop classification.

SVM which is one of the machine learning algorithms has been implemented here since it's superior performance on crop and land cover classification compared to conventional classification algorithms has been proven in many studies.(Foody and Mathur, 2004; Mathur and Foody, 2008; Waske and Benediktsson, 2007).

In this study, the potential use of three different vegetation indices of RapidEye imagery on crop type classification as well as the effect of each indices on classification accuracy were investigated. Original bands of RapidEye imagery were excluded and classification was performed with only three vegetation indices.

\section{STUDY AREA}

The study area is located in Aegean region of Turkey and comprised of approximately $17.3 \mathrm{~km}^{2}$ of agricultural areas. It covers nine land use classes which are corn (first crop, second crop), cotton (well developed, moderate developed, weak developed), soil (wet, moist, dry) and water surface. Major sources of income are agriculture and tourism in the region and most important agricultural products are olives, figs, grapes and several vegetables. Therefore the sustainable management of the agricultural areas is important for local authorities at the region.

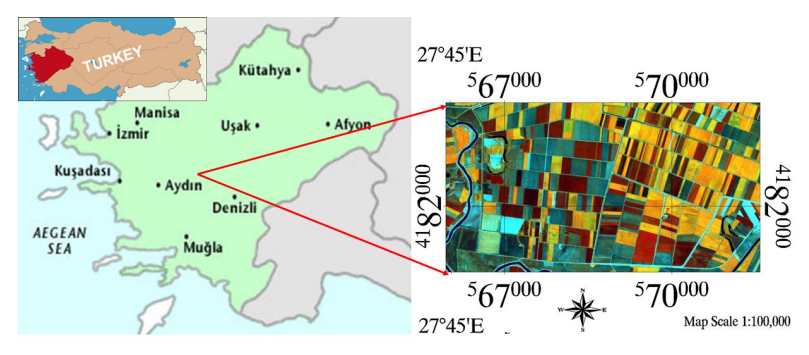

Figure 1.Study area

\section{MATERIALS AND METHODS}

\subsection{RapidEye Data and Vegetation Indices}

RapidEye is the first high-resolution multispectral satellite system incorporating red-edge channel, which makes this system different and privileged from the other multispectral satellite systems (Schuster et al. 2012).

The RapidEye data provides five spectral bands with 5-meter spatial resolution.

\begin{tabular}{|ll|}
\hline Product Attribute & Description \\
\hline Product Type & Level 3A (orthoproduct) \\
Pixel size (orthorectified) & $5 \mathrm{~m}$ \\
& Blue $(440-510 \mathrm{~nm})$ \\
& Green $(520-590 \mathrm{~nm})$ \\
Spectral Bands & Red $(630-685 \mathrm{~nm})$ \\
& Red-edge $(690-730 \mathrm{~nm})$ \\
& Near-Infrared(760-850) \\
Bit Depth & 16-bit unsigned integers \\
\hline
\end{tabular}

Table 1.Specifications of data

Data was delivered in Level 3A (orthoproduct) in which radiometric, sensor and geometric corrections have been applied to the data.

Three different spectral indices calculated in this study. The band number $2,3,4,5$ refers to green $(520-590 \mathrm{~nm})$, red $(630-$ $685 \mathrm{~nm})$, red-edge $(690-730 \mathrm{~nm})$ and near-infrared $(760-$ $850 \mathrm{~nm})$, respectively in table 2 .

\begin{tabular}{|c|c|}
\hline $\begin{array}{l}\text { Vegetation } \\
\text { Index }\end{array}$ & Equation \\
\hline $\begin{array}{l}\text { NDVI } \\
\text { (Tucker, 1979) }\end{array}$ & $N D V I=\left(R_{\text {band } 5}-R_{\text {band3 }}\right) /\left(R_{\text {band } 5}+R_{\text {band3 }}\right)$ \\
\hline $\begin{array}{l}\text { GNDVI } \\
\text { (Gitelson et } \\
\text { al.,1979) }\end{array}$ & $G N D V I=\left(R_{\text {band } 5}-R_{\text {band } 2}\right) /\left(R_{\text {band } 5}+R_{\text {band } 2}\right)$ \\
\hline $\begin{array}{l}\text { NDRE } \\
\text { (Barnes et } \\
\text { al.,2000) }\end{array}$ & $N D R E=\left(R_{\text {band } 5}-R_{\text {band } 4}\right) /\left(R_{\text {band } 5}+R_{\text {band } 4}\right)$ \\
\hline
\end{tabular}

Table 2.Vegetation (Spectral) indices

\subsection{Image Classification}

The Support Vector Machine (SVM) which is one of the supervised machine learning methods is based on statistical learning theory. The main idea for SVM classification is the fitting the optimal hyperplane separating the two classes. (Vapnik, 1995; Huang et al., 2002). Kernel functions could construct the optimal hyperplane for the complex data which cannot be separated with linear hyperplanes (Huang et al., 2002). Radial Basis Function (RBF) was selected for SVM classification here.

The determination of the optimum parameters of cost (C) and kernel width $(\sigma)$ is required and it is determined as 200 and 0,333 for cost and kernel width, respectively.

Non-parametric supervised learning algorithms like random forest and support vector machines which do not rely on any prior data distribution of classes have been commonly preferred in image classification and successfully applied on crop classification recently (Foody and Martur 2004; Waske and Benediktsson 2007; Martur and Foody 2008; Schuster et al. 2012; Löw et al. 2013; Adelabu et al. 2014).

Only very basic information on SVM has been provided here and reader could reach the detailed information and theoretical background of SVM at Vapnik (1995), Huang et al. (2002) and Chang and Lin (2011).

\section{SPECTRAL ANALYSIS}

Four different sets of spectral features have been used here for the analysis of the potential use of vegetation indices from RapidEye imagery as well as the contribution and sensitivity of each spectral band on classification accuracy.

\begin{tabular}{|lcccc|}
\hline Band/Analysi & Analysis & Analysis & Analysi & Analysi \\
s & A & B & s C & s D \\
\hline NDVI & $\checkmark$ & $x$ & $\checkmark$ & $\checkmark$ \\
GNDVI & $\checkmark$ & $\checkmark$ & $x$ & $\checkmark$ \\
NDRE & $\checkmark$ & $\checkmark$ & $\checkmark$ & $x$ \\
\hline
\end{tabular}

Table 3.Sets of spectral features 
Single-band image classification has been carried out as an additional step for the analysis.

\section{ACCURACY ASSESSMENT}

The accuracy of the classified images was assessed using overall accuracy and kappa coefficient. Classification results of the analysis and single-band image classifications can be seen at Table 4 and Table 5 , respectively

\begin{tabular}{|lc|c|}
\hline Analysis & Overall Accuracy $(\%)$ & Kappa coefficient \\
\hline A & 87,46 & 0,8566 \\
B & 86,41 & 0,8442 \\
C & 86,41 & 0,8444 \\
D & 56,45 & 0,5114 \\
\hline
\end{tabular}

Table 4.Classification accuracy of analysis

\begin{tabular}{|lcc|}
\hline Band & Overall Accuracy (\%) & Kappa coefficient \\
\hline NDVI & 57,84 & 0,5260 \\
GNDVI & 53,31 & 0,4742 \\
NDRE & 63,42 & 0,5851 \\
\hline
\end{tabular}

Table 4.Classification accuracy of single-band images

Classified images of the analysis and single-band images can be seen at Figure2 and Figure3, respectively.
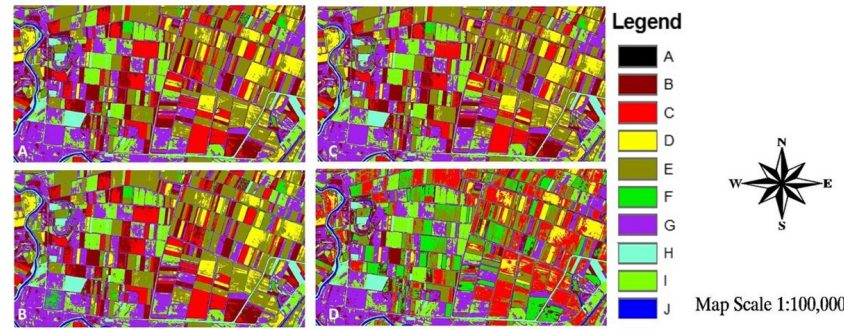

Figure 2.Classified images (Analysis A, B, C, D)

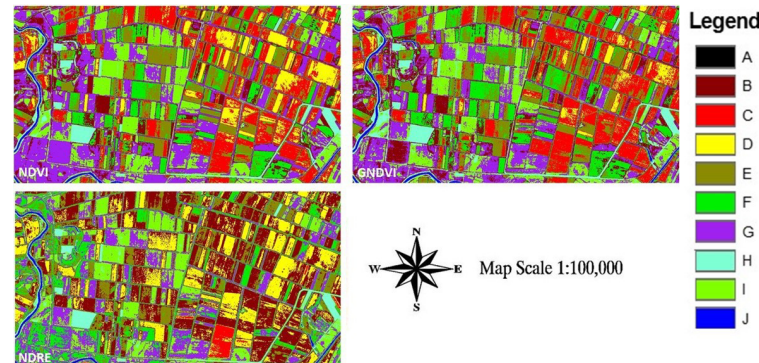

Figure 3.Single-band image classification

In the legend, class of interests are represented by A, B, C, D, E, F, G, H, I, J for unclassified, first crop corn, second crop corn, well developed cotton, moderate developed cotton, weak developed cotton, wet soil, moist soil, dry soil and water surface, respectively.

The individual contributions of spectral features on classification accuracy could be derived from Table 4 . These are $1,05 \%, 1,05 \%$ and $31,01 \%$ for NDVI, GNDVI and NDRE, respectively.

\section{CONCLUSION}

Potential use of three different vegetation indices of RapidEye imagery on crop type classification as well as individual contribution of each vegetation indices on classification accuracy have been investigated using support vector machine. The results of this study indicate that vegetation indices derived from original spectral bands of RapidEye imagery could be used for crop classification and show satisfactory results.

Single band image classification has been also implemented to analyse the individual performance of spectral bands on image classification accuracy. Our results demonstrate that NDRE has more contribution than other indices on image classification accuracy. This study also proves the efficient use of support vector machines for crop classification as it was proven in the previous studies as well.

The evaluation of the any other vegetation indices incorporating NIR band from RapidEye imagery should be done as future work using different classification techniques such as random forest or object-based classification as an addition to support vector machines.

\section{REFERENCES}

Adelabu, S., O. Mutanga, et al. 2014. "Evaluating the impact of red-edge band from Rapideye image for classifying insect defoliation levels." ISPRS Journal of Photogrammetry and Remote Sensing 95(0): 34-41.

Barnes, E. M., T. R. Clarke, et al. 2000. "Coincident detection of crop water stress, nitrogen status and canopy density using ground based multispectral data." Proc. 5th Int. Conf. Precis Agric. Bloomington, MN, USA.

Bauer, M. E., \& Cipra, J. E. 1973. Identification of agricultural crops by computer processing of ERTS MSS data. LARS Technical Reports. 20. http://docs.lib.purdue.edu/larstech/20. W. Lafayette, IN: Purdue Univ

Branca G, McCarthy N, Lipper L, Jolejole MC. 2011. ClimateSmart Agriculture: A Synthesis of Empirical Evidence of Food Security and Mitigation Benefits from Improved Cropland Management. Mitigation of Climate Change in Agriculture Series no. 3. Food and Agriculture Organization of the United Nations (FAO), Rome, Italy.

Chang, C.-C and Lin C.-J. (2011). "LIBSVM: A library for support vector machines." ACM Trans. Intell. Syst. Technol. 2(3): 1-27.

Eitel, J. U. H., L. A. Vierling, et al. 2011. "Broadband, red-edge information from satellites improves early stress detection in a New Mexico conifer woodland." Remote Sensing of Environment 115(12): 3640-3646

Foody, G. M. and A. Mathur 2004. "Toward intelligent training of supervised image classifications: directing training data acquisition for SVM classification." Remote Sensing of Environment 93(1-2): 107-117. 
Fundamentals of Remote Sensing, Natural Resources Canada, 2013,

http://www.nrcan.gc.ca/sites/www.nrcan.gc.ca/files/earthscienc es/pdf/resource/tutor/fundam/pdf/fundamentals_e.pdf

Gitelson, A. A., M. N. Merzlyak, et al. (1996). "Detection of Red Edge Position and Chlorophyll Content by Reflectance Measurements Near 700 nm." Journal of Plant Physiology 148(3-4): 501-508.

Huang, C., L. S. Davis, et al. 2002. "An assessment of support vector machines for land cover classification." International Journal of Remote Sensing 23(4): 725-749.

Jackson, R. D. and A. R. Huete 1991. "Interpreting vegetation indices." Preventive Veterinary Medicine 11(3-4): 185-200.

Jewell, N. 1989. "An evaluation of multi-date SPOT data for agriculture and land use mapping in the United Kingdom." International Journal of Remote Sensing 10(6): 939-951.

Löw, F., U. Michel, et al. 2013. "Impact of feature selection on the accuracy and spatial uncertainty of per-field crop classification using Support Vector Machines." ISPRS Journal of Photogrammetry and Remote Sensing 85(0): 102-119.

Marx. A, 2013. "The impact of the RapidEye Red Edge band in Mapping Defoliation Symptoms", ESA Living Planet Symposium, Edinburg, United Kingdom http://seom.esa.int/LPS13/5405ddfb/

Mathur, A. and G. M. Foody 2008. "Crop classification by support vector machine with intelligently selected training data for an operational application." International Journal of Remote Sensing 29(8): 2227-2240.

Mulla, D. J. 2013. "Twenty five years of remote sensing in precision agriculture: Key advances and remaining knowledge gaps." Biosystems Engineering 114(4): 358-371.

Schuster, C., M. Förster, et al. 2012. "Testing the red edge channel for improving land-use classifications based on highresolution multi-spectral satellite data." International Journal of Remote Sensing 33(17): 5583-5599.

Tigges, J., T. Lakes, et al. 2013. "Urban vegetation classification: Benefits of multitemporal RapidEye satellite data." Remote Sensing of Environment 136(0): 66-75.

Tucker, C. J. (1979). "Red and photographic infrared linear combinations for monitoring vegetation." Remote Sensing of Environment 8(2): 127-150.

Vapnik, V. N. (1995). The nature of statistical learning theory, Springer-Verlag New York, Inc.

Waske, B. and J. A. Benediktsson 2007. "Fusion of Support Vector Machines for Classification of Multisensor Data." Geoscience and Remote Sensing, IEEE Transactions on 45(12): 3858-3866. 